THE CHEMISTRY OF THE GLUTACONIC ACIDS. PART v. 1557

\title{
CLXVIII.-The Chemistry of the Glutaconic Acids. Part V. The Preparation of Esters of the Labile Acids.
}

By Norman Bland and Jocelyn Field Thorpe.

UP to the present time four acids of the glutaconic series containing the movable or mobile hydrogen atom have been isolated in two modifications, namely:

$\begin{array}{llccc}\text { a-Methylglutaconic acid, m.p. } & 145-146^{\circ} & \text { and } & 118^{\circ} \\ \text { a-Ethylglutaconic acid } & , & 133-134 & , & 108 \\ \text { a-Benzylglutaconic acid } & , & 153-154 & , & 139 \\ \text { B-Methylglutaconic arid } & , & 147 & , & 115-116\end{array}$

The experimental evidence recorded in the previous parts of this series has led us to the conclusion that these isomeric acids are not related to one another in the same manner as fumaric and maleic acids, but have a difference in structure due to the position of the tautomeric hydrogen atom within the molecule. Thus the isomerides of lower melting point are regarded as labile acids formed from the hydroxy-anhydrides under conditions which cause the hydrogen atom to come to rest within the carbonyl system; the modifications of higher melting point, on the other hand, are the normal acids similar in structure to isophthalic acid, which are produced under conditions which allow the hydrogen atom to pass into its more stable position within the three-carbon system. In this way the two modifications of, for example, $\beta$-methylglutaconic acid can be represented by the formulæ:<smiles>CC(C(=O)O)C(C)C(=O)O</smiles>

Normal acid. M.p. $147^{\circ}$.<smiles>CC(=CC(=O)O)CC(=O)O</smiles>

Labile acid. M.p. $115-116^{\circ}$.

* Hilditch and Smiles have shown that the so-called additive compound of triethylsulphonium iodide with mercuric iodide, $\left(\mathrm{C}_{2} \mathrm{H}_{5}\right)_{3} \mathrm{SI}, \mathrm{HgI}_{2}$, can be really regarded as au "atomic" compound, $\left(\mathrm{C}_{2} \mathrm{H}_{5}\right)_{3} \mathrm{SI}_{2} \cdot \mathrm{HgI}$ (Trans., 1907, 91, 1395). 
Investigation has shown that it is usually possible to isolate the labile forms of the acids by hydrating the hydroxy-anhydrides by strong aqueous alkali or by dilute alkali in the presence of casein, thus:

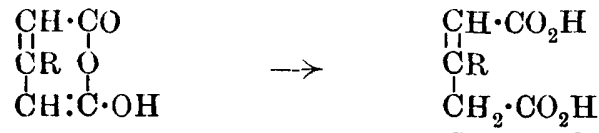

Labile acid.

This method is, however, open to the objection that it is a very difficult matter to prevent the hydrogen atom introduced by the hydration of the hydroxy-anhydride from passing, at the moment of fission of the pyrone ring, into the three-carbon system, and in this way yielding the normal acid. Thus, although it has been shown that the presence of the methyl group in $\beta$-methylglutaconic acid confers considerable stability on the labile form of the acid, it is a matter of some difficulty to obtain the labile acid by the hydration of the hydroxy-anhydride.

It seemed to us probable that a general method for the preparation of the labile acids of this type could be found if their open-chain enolic esters, containing a potentially mobile hydrogen atom, were hydrolysed by alkali, and, as a matter of fact, an examination of the literature quickly supplied evidence in favour of this assumption.

During his experiments on the preparation of the two modifications of $\beta$-methylglutaconic acid, Feist (Annalen, 1906, 345, 64, $65)$ discovered the remarkable fact that when ethyl isodehydracetate is hydrolysed by the theoretical amount of alkali, the acid of higher melting point (normal acid) is the sole product:

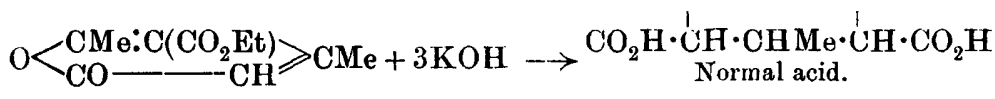

Type (x).

$$
\mathrm{Me} \cdot \mathrm{CO}_{2} \mathrm{H}+\mathrm{EtOH}
$$

whereas the hydrolysis by alkali of the condensation product formed from ethyl tetrolate and ethyl malonate yielded the acid of lower melting point (labile acid) in a pure condition :

$$
\begin{gathered}
\mathrm{CM}+: \mathrm{C} \cdot \mathrm{CO}_{2} \mathrm{Et}+\mathrm{HCNa}\left(\mathrm{CO}_{2} \mathrm{Et}\right)_{2} \stackrel{*}{\rightarrow} \\
\left(\mathrm{CO}_{2} \mathrm{Et}\right)_{2} \mathrm{C}: \mathrm{CMe} \cdot \mathrm{CH}: \mathrm{C}(\mathrm{OH}) \cdot \mathrm{ONa} \uparrow \rightarrow \mathrm{CO}_{2} \mathrm{H} \cdot \mathrm{CH}: \mathrm{CMe}^{+} \cdot \mathrm{CH}_{2} \cdot \mathrm{CO}_{2} \mathrm{H}
\end{gathered}
$$

Labile acid.

It is evident that the fission of the pyrone ring of ethyl isodehydracetate causes the hydrogen to pass into the three-carbon system. In fact, the analogy between the behaviour of this sub-

+ The reason for assigning this structur to the sodium compounl has been given (compare this vol., p. 250). 
stance and that of the hydroxy-anhydride is further emphasised by the observation made by Feist that the presence of a large excess of alkali leads to the formation of the acid of lower melting point (labile acid) (compare this vol., p. 866).

On the other hand, the condensation product (I) of ethy] tetrolate and ethyl sodiomalonate contains a hydrogen atom, marked *, which is potentially the mobile hydrogen atom. The hydrolysis of this ester by alkali gives therefore the labile form of the acid, because the ester retains its structure during hydrolysis, and the hydrogen atom remains within the carbonyl system of the acid.

It is evident that the alkylation of the sodium compound (I) will lead to the production of an ester (II), which, in the form of its sodium derivative, will have the structure (III):

$$
\left(\mathrm{CO}_{2} \mathrm{Et}\right)_{2} \mathrm{C:CM} \cdot \underset{\mathrm{CO}_{2} \mathrm{Et}}{\mathrm{CHR}} \rightarrow \mathrm{OEt} \cdot\left({ }^{\prime}(\mathrm{ONa}): \mathrm{C}\left(\mathrm{CO}_{2} \mathrm{Et}\right) \cdot \mathrm{CMe}: \underset{\mathrm{CO}_{2} \mathrm{Et}}{\mathrm{CR}}\right.
$$

This sodium derivative does not contain a potentially mobile hydrogen atom, and it will therefore behave as the corresponding cyano-ester (this vol., p. 878), and give a mixture of the normal and labile esters when the sodium compound is treated with water:

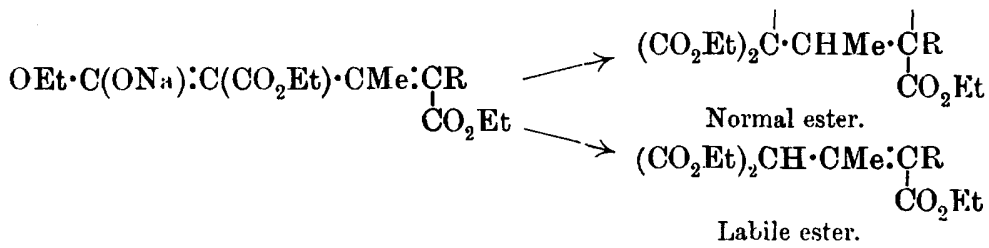

This assumption was verified by experiment; the labile ester ( $\mathbf{R}$ being methyl) was isolated in the manner previously described for the cyano-ester, and its structure proved by the formation of the labile acid from it on alkaline hydrolysis:

$\left(\mathrm{CO}_{2} \mathrm{Et}\right)_{2} \mathrm{CH} \cdot \mathrm{CMe}: \mathrm{CMe} \cdot \mathrm{CO}_{2} \mathrm{Et} \rightarrow \mathrm{CO}_{2} \mathrm{H} \cdot \mathrm{CH}_{2} \cdot \mathrm{CMe}: \mathrm{CMe} \cdot \mathrm{CO}_{2} \mathrm{H}$.

This experiment supplied the proof of structure which could not be obtained in the case of the cyano-esters themselves, because these substances are entirely converted into derivatives of $2: 6$-dihydroxypyridine on alkaline hydrolysis :

$$
\mathrm{CO}_{2} \mathrm{Et} \cdot \mathrm{CH}(\mathrm{CN}) \cdot \mathrm{CMe}: \mathrm{CMe} \cdot \mathrm{CO}_{2} \mathrm{Et} \rightarrow \quad \mathrm{CMe} \leqslant \mathrm{CH}_{\mathrm{CH} \cdot \mathrm{C}(\mathrm{OH})}^{\mathrm{CH}(\mathrm{OH})} \geqslant \mathrm{N} .
$$

The labile and normal esters of carbethoxy- $\alpha \beta$-dimethylglutaconic acid produced in the above way are analogous to the corresponding cyano-esters. The labile ester is a desmotropic substance, forming equilibrium mixtures of the ketonic and enolic forms at the ordinary temperature. The yield is, however, only about 35 per 
cent. of the ester converted, and this fact, combined with the tiresome nature of the preparation of ethyl tetrolate caused us to search for some other method by which we could prepare large quantities of the labile esters, since it is our intention in the near future to subject the two types to an extended chemical investigation. Ultimately the following process was found to give the desired result.

Ethyl isodehydracetate (IV) is a substance which can be prepared in large quantities by the action of dry hydrogen chloride on ethyl acetoacetate. We find that the pyrone ring is at once broken by alcoholic sodium ethoxide at $0^{\circ}$, and that a good yield of a yellow sodium compound is obtained from which the corresponding ester can be prepared through the agency of carbon dioxide.

From the fact that this ester gives a pronounced coloration with ferric chloride and is reconverted into the pyrone derivative on distillation, it may be inferred that its structure is represented by formula (V), and that the sodium compound has the formula (VI):

$\mathrm{O}<\mathrm{CO}-\mathrm{CMe} \mathrm{C}\left(\mathrm{CO}_{2} \mathrm{E}(\cdot)\right) \geqslant \mathrm{CMe}+\mathrm{NaOEt} \rightarrow$ (IV.)

$\mathrm{NaO} \cdot \mathrm{CMe}: \mathrm{C}\left(\mathrm{CO}_{2} \mathrm{Et}\right) \cdot \mathrm{CMe}: \underset{\mathrm{C}}{\mathrm{C}} \mathrm{H}$

(VI.)
$\mathrm{COM} \cdot \mathrm{CH}\left(\mathrm{CO}_{2} \mathrm{Et}\right) \cdot \mathrm{CMe}: \underset{\mathrm{CO}_{2} \mathrm{Et}}{\mathrm{CH}}$

In other words, the presence of the ketonic group causes the hydrogen atom to be retained on the adjacent carbon atom, and renders this substance an exception to the rule given in a previous paper (this vol., p. 250), namely, that derivatives of this type react with sodium ethoxide to form sodium derivatives, which retain the mobile (or potentially mobile) hydrogen atom.

That this is actually the case is at once shown by a comparison of the acetyl ester with the corresponding carboxylic ester (VII), for the first-named, since it does not contain the potentially mobile hydrogen atom, reacts with sodium ethoxide at the ordinary temperature, yielding ethyl acetate and the dicarboxylic ester, whereas the latter, which contains this hydrogen atom, is quite unacted on by sodium ethoxide (compare Trans., 1911, 99, 192):

$\mathrm{NaO} \cdot \mathrm{CMe}: \mathrm{C}\left(\mathrm{CO}_{2} \mathrm{Et}\right) \cdot \mathrm{CMe}: \mathrm{CH} \cdot \mathrm{CO}_{2} \mathrm{Et}+\mathrm{EtOH} \rightarrow$

$\mathrm{NaO} \cdot \mathrm{C}(\mathrm{OEt}): \mathrm{CH} \cdot \mathrm{CM \theta}: \mathrm{CH} \cdot \mathrm{CO}_{2} \mathrm{Et}+\mathrm{CH}_{3} \cdot \mathrm{CO}_{2} \mathrm{Et}$

(VIII.)

$\left(\mathrm{CO}_{2} \mathrm{Et}\right)_{2} \mathrm{C:CMe} \cdot \mathrm{CH}: \mathrm{C}(\mathrm{OEt}) \cdot \mathrm{ONa}$ (VII.)

Moreover, it is evident that the sodium derivative of the dibasic ester (VIII) now contains the potentially mobile hydrogen atom 
$\left({ }^{*}\right)$, and that it will react with water, yielding the labile ester (IX) as sole product:

$$
\mathrm{NaO} \cdot \mathrm{C}(\mathrm{OEt}): \mathrm{CH} \cdot \mathrm{CMe}: \mathrm{CH} \cdot \mathrm{CO}_{2} \mathrm{Et} \rightarrow \mathrm{CO}_{2} \mathrm{Et} \cdot \mathrm{CH}_{2} \cdot \mathrm{CMe}: \mathrm{CH} \cdot \mathrm{CO}_{2} \mathrm{Et}
$$

Experiment shows that this is actually the case, and that the labile ester of $\beta$-methylglutaconic acid can be prepared in large quantities by this method. The properties of the ester show that it is the pure labile ester. The corresponding ester of the normal acid is best prepared from the normal acid by the aid of alcohol and sulphuric acid; the two isomerides boil at practically the same temperature, but it is hoped that further investigation will reveal important physical and chemical differences.

It is interesting to note that the hydrogen ethyl salts of the two acids are different substances. That from the normal acid melts at $73^{\circ}$, that from the labile acid is a liquid. Since these salts yield their respective acids under the same conditions of alkaline hydrolysis, it is to be concluded that they retain the normal and labile structures.

Having established a method for the preparation of the labile esters of this type, it was clear that we had to hand a means of isolating the labile esters of the corresponding alkyl derivatives substituted on one of the terminal carbon atoms, and it is evident that from these esters the labile forms of the alkyl acids could be prepared.

It is a simple matter to convert ethyl isodehydracetate into the alkylated dicarboxylic ester, for when the pyrone derivative is treated with alcoholic sodium ethoxide and the alkyl iodide at $0^{\circ}$, it is quickly and completely transformed into ethyl acetate and the desired ester :

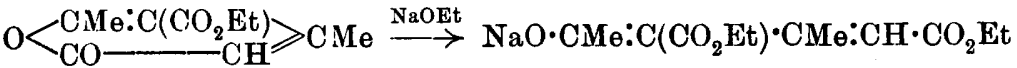

$$
\begin{aligned}
& +\mathrm{RI} \rightarrow \mathrm{CO}_{2} \mathrm{Et} \cdot \mathrm{CR}: \mathrm{CMe}^{\circ} \mathrm{CH}_{2} \cdot \mathrm{CO}_{2} \mathrm{Et}+\mathrm{NaI}+\mathrm{CH}_{3} \cdot \mathrm{CO}_{2} \mathrm{Et} \text {. }
\end{aligned}
$$

It is advisable in this reaction to have a slight excess of sodium ethoxide present, but it is certain, both from our experiments as well as from those of Feist and Beyer (Annalen, 1906, 345, 123) that the sodium compounds of the dibasic esters are largely, if not entirely, dissociated in alcohol, and consequently the free sodium ethoxide necessary to effect the elimination of the acetyl group is present throughout the reaction.

It is evident that the dialkylated esters produced in this way are the labile esters, because, since the alkyl group enters on the $\gamma$-carbon atom, it follows that the sodium compounds of the esters, which are certainly intermediate products in the reaction, retain 
a potentially mobile hydrogen $\left({ }^{*}\right)$, and will therefore yield the labile esters :

$\mathrm{CO}_{2} \mathrm{El} \cdot \mathrm{CR}: \mathrm{CMe}^{\circ} \mathrm{CH}: \mathrm{C}(\mathrm{OEt}) \cdot \mathrm{ONa} \rightarrow \mathrm{CO}_{2} \mathrm{Et} \cdot \mathrm{CR}: \mathrm{CMe}^{2} \mathrm{CH}_{2} \cdot \mathrm{CO}_{2} \mathrm{Et}$.

It is perhaps desirable to emphasise the fact that probably it is only by such a method as this that the labile esters of the dialkylated esters can be propared. It might be supposed that this object could be attained by alkylating the dicarboxylic esters. In this case, however, the alkyl group enters on the $a$-carbon atom yielding the $a$-alkyl derivative, a condition which we have shown to be unstable:

\section{$\mathrm{CO}_{2} \mathrm{Et} \cdot \mathrm{CH}: \mathrm{CMe}_{\theta} \cdot \mathrm{CH}: \mathrm{C}(\mathrm{OEt}) \cdot \mathrm{ONa} \rightarrow \mathrm{CO}_{2} \mathrm{Et} \cdot \mathrm{CH}: \mathrm{CM} \mathrm{M}_{\bullet} \cdot \mathrm{CHR} \cdot \mathrm{CO}_{2} \mathrm{Et}$ $\rightarrow \mathrm{CO}_{2} \mathrm{Et} \cdot \stackrel{\mathrm{C}}{\mathrm{CH}} \cdot \mathrm{CHM} \cdot \stackrel{\dot{C} \mathrm{C}}{\mathrm{C}} \cdot \mathrm{CO}_{2} \mathrm{Et}$.}

The hydrogen atom therefore passes away from the substituted position towards the more remote carbon atom of the system. To do this it must pass through its most stable position within the three-carbon system, and therefore, as we have proved by experiment, the normal esters are the sole products of reactions of this type (compare this vol., p. 887).

It is, of course, npparent that the labile esters should be produced by the action of water on their sodium derivatives in the manner indicated by the equation given above, but when once the normal esters of this type have been isolated they do not seem to possess any tendency to form sodium derivatives with alcoholic sodium ethoxide (compare Annalen, 1906, 345, 123).

In this way we have therefore been able to prepare the labile esters of both $\beta$-methyl- $\alpha$-ethylglutaconic acid and of $\alpha \beta$-dimethylglutaconic acid, and have prepared the corresponding labile acids:

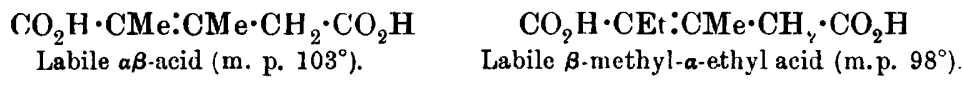

As compared with their normal isomerides, these acids possess the characteristic differences of the normal and labile acids of the series. The labile acids are very stable towards alkali, but slowly pass into the normal forms on treatment with hydrochloric acid. Both modifications give the hydroxy-anhydride with equal readiness, and the hydroxy-anhydrides, on hydration with water, give the normal acids. If, however, hydration is effected by strong alkali or by dilute alkali in the presence of casein, the labile acids are produced. Whereas the two modifications of the a-mono-substituted derivatives cannot be distinguished from one another by means of their salts, the two states of the acids described in this paper show important differences in this respect. Thus the normal acids are characterised by giving insoluble and crystalline barium, 
as well as calcium, salts, whilst the salts of the labile acids with these metals are soluble in water.

The normal acid and the hydroxy-anhydride of $\alpha \beta$-dimethylglutaconic acid, as well as its aniline derivatives, have been already described (Trans., 1911, 99, 2221). The normal form of $\beta$-methyl$\alpha$-ethylglutaconic acid has also been described (Trans., 1905, 87, 1709), but the substance melting at $53^{\circ}$ described in that paper as the anhydride is in reality the hydroxy-anhydride, since it behaves on titration as a monobasic acid, yielding salts in accordance with the equation :

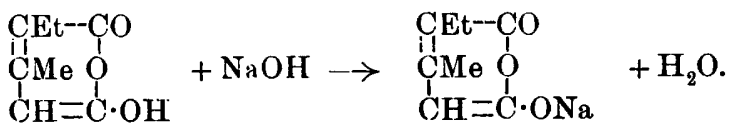

The semianilide, melting at $129^{\circ}$, which is formed by the action of aniline on the hydroxy-anhydride, passes into the hydroxy-anil when heated, and the same substance is produced both from the normal and labile acids by the action of aniline at a high temperature :<smiles>CC(C)ONc1ccccc1</smiles>

M. p. $129^{\circ}$.

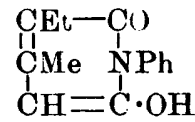

M. p. $95^{\circ}$.

The derivatives of $\beta$-methyl $\alpha$-ethylglutaconic acid are therefore as follows:

Normal acid. Labile acid. Hydroxyanhydride. Anilic acid. Hydroxyanil. $\begin{array}{lllll}164^{\circ} & 98^{\circ} & 53^{\circ} & 129^{\circ} & 95^{\circ}\end{array}$

EXPERIMENTAL.

Normal Ethyl Carbethoxy-aß-dimethylglutaconate, $\left(\mathrm{CO}_{2} \mathrm{Et}\right)_{2} \mathrm{C} \cdot \mathrm{CH} \mathrm{Me} \cdot \stackrel{\mathrm{C}}{\mathrm{C}} \mathrm{Me} \cdot \mathrm{CO}_{2} \mathrm{Et}$

The normal ester of the above formula is the sole product formed when an alcoholic solution of the sodium compound,

$\left(\mathrm{CO}_{2} \mathrm{Et}\right)_{2} \mathrm{C:CMe} \cdot \mathrm{CH}: \mathrm{C}(\mathrm{ONa}) \cdot \mathrm{OEt}$,

which is produced in the condensation of ethyl tetrolate and ethyl sodiomalonate (Feist, Annalen, 1906, 345, 82), is heated on the water-bath with excess of methyl iodide. It boils at $177^{\circ} / 20 \mathrm{~mm}$., is not extracted from its ethereal solution by 10 per cent. aqueous potassium hydroxide, and is not coloured by ferric chloride:

0.2103 gave $0.4541 \mathrm{CO}_{2}$ and $0.1480 \mathrm{H}_{2} \mathrm{O} . \mathrm{C}=58.90 ; \mathrm{H}=7.82$.

$$
\mathrm{C}_{14} \mathrm{H}_{22} \mathrm{O}_{6} \text { requires } \mathrm{C}=58 \cdot 7 ; \mathrm{H}=7 \cdot 7 \text { per cent }
$$

The ester is converted into normal $\alpha \beta$-dimethylglutaconic acid, melting at $148^{\circ}$, on both acid and alkaline hydrolysis. 


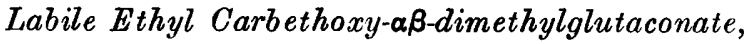 $\left(\mathrm{CO}_{2} \mathrm{Et}\right)_{2} \mathrm{CH} \cdot \mathrm{CM} \mathrm{e}: \mathrm{CMe} \cdot \mathrm{CO}_{2} \mathrm{Et}$.}

When an alcoholic solution of the sodium compound formed by the action of an equivalent amount of alcoholic sodium ethoxide on the normal ester is poured into twice its volume of water (twelve times the weight of alcohol was used to dissolve the sodium), about 65 per cent. regenerated normal ester is extracted by ether, and the remainder is obtained as a mixture of the ketonic and enolic forms of the labile ester on passing carbon dioxide into the yellow aqueous solution.

The equilibrium mixture closely resembles the normal ester in appearance, and boils at $178^{\circ} / 20 \mathrm{~mm}$; it gives a reddish-purple coloration with ferric chloride:

0.1997 gave $0.4303 \mathrm{CO}_{2}$ and $0.1412 \mathrm{H}_{2} \mathrm{O} . \quad \mathrm{C}=58 \cdot 76 ; \mathrm{H}=7 \cdot 85$. $\mathrm{C}_{14} \mathrm{H}_{22} \mathrm{O}_{6}$ requires $\mathrm{C}=58 \cdot 7 ; \mathrm{H}=7 \cdot 7$ per cent.

When the equilibrium mixture is dissolved in ether, and the solution is shaken with 10 per cent. aqueous potassium hydroxide, about 15 per cent. is extracted as the yellow potassium compound. Carbon dioxide liberates the enolic form from this solution at low temperatures (ice and salt), and the substance formed in this manner is proved to be an almost pure specimen of this individual from the fact that it is completely extracted from its solution in ether by aqueous potassium hydroxide. It gives a deep red ferric coloration with ferric chloride, but slowly reverts to the equilibrium mixture at the ordinary temperature, a change which is rapidly completed on distillation. The ethereal solution from which the enolic individual has been extracted gives at first no coloration with ferric chloride, but rapidly acquires this property, owing to the gradual restoration of equilibrium between the two forms. After remaining for a short time more of the yellow potassium compound can be extracted by aqueous potassium hydroxide. The labile ester, when hydrolysed by acids, is converted into the normal acid, but when hydrolysed by alkali, a mixture of the normal and labile acids is obtained, from which the latter can be isolated by the aid of the barium salt; for this purpose the mixture is converted into the ammonium salt, excess of barium chloride added, and the whole evaporated to dryness. The soluble barium salt, extracted by cold water, gives, when acidified and extracted by ether, an acid which crystallises from benzene, and then melts at $103^{\circ}$. This acid is described fully later in the paper. The insoluble barium salt gave the normal acid, melting at $148^{\circ}$, on treatment in the same way. 


\section{Ethyl a-A cetyl-B-methylglutaconate, $\mathrm{CO}_{2} \mathrm{Et} \cdot \mathrm{CHAc} \cdot \mathrm{CMe}: \mathrm{CH} \cdot \mathrm{CO}_{2} \mathrm{Et}$.}

This ester can be prepared in the following way. Sodium (11.5 grams) is dissolved in alcohol and added to 100 grams of ethyl isodehydracetate (Duisberg, Ber., 1882, 15, 1387 ; Annalen, 1882, 213, 177), mixed with an equal volume of alcohol, and cooled to $-5^{\circ}$. The addition must be effected gradually, and the temperature at no stage must exceed $0^{\circ}$. The deep yellow solution is then diluted with an equal volume of water, and carbon dioxide passed into it until the colour is discharged, when the precipitated oil is extracted by ether. It is a moderately viscid liquid, which is coloured deep purple in alcoholic solution by ferric chloride:

0.1856 gave $0.4041 \mathrm{CO}_{2}$ and $0.1252 \mathrm{H}_{2} \mathrm{O} . \quad \mathrm{C}=59.38 ; \mathrm{H}=7.49$.

$$
\mathrm{C}_{12} \mathrm{H}_{18} \mathrm{O}_{i j} \text { requires } \mathrm{C}=59 \cdot 5 ; \mathrm{H}=7 \cdot 4 \text { per cent. }
$$

The ester is completely extracted from its solution in ether by aqueous potassium hydroxide, and is therefore probatly enolic in structure. When distilled, it passes almost completely into the pyrone derivative from which it was derived.

\section{Labile Ethyl B-Methylglutaconate, $\mathrm{CO}_{2} \mathrm{Et} \cdot \mathrm{CH}_{2} \cdot \mathrm{CMe}: \mathrm{CH} \cdot \mathrm{CO}_{2} \mathrm{Et}$.}

In order to prepare considerable quantities of the substance, 23 grams of sodium were dissolved in 270 grams of alcohol and gradually mixed with 196 grams of ethyl isodehydracetate, the solution being cooled under running water. After being kept for two hours at "nom temperature, water was added, and the precipitated oil extracted by ether. The ester boils at $167^{\circ} / 68 \mathrm{~mm}$. as a clear, mobile liquid. The yield was 75 per cent. of the theoretical amount:

0.1862 gave $0.4089 \mathrm{CO}_{2}$ and $0.1355 \mathrm{H}_{2} \mathrm{O} . \quad \mathrm{C}=59 \cdot 89 ; \mathrm{H}=8.08$.

$$
\mathrm{C}_{10} \mathrm{H}_{16} \mathrm{O}_{4} \text { requires } \mathrm{C}=60.0 ; \mathrm{H}=8.0 \text { per cent. }
$$

The structure of the ester was proved by the formation of the labile acid (m. p. $115-116^{\circ}$ ) by hydrolysis with alcoholic potassium hydroxide. Hydrolysis with hydrochloric acid yielded a mixture of the normal and labile acids. A quantity of acid material remains dissolved in the alkaline liquid after extracting the above ester, and can be obtained on acidifying and extracting with ether. The greater portion of this is the labile acid ester, described in the nezt paragraph; but the remainder consists of a substance of higher molecular weight. The whole was etherified by alcohol and sulphuric acid, when the ethereal solution of the product slowly deposited crystals, which, on recrystallisation from alcohol, yielded well-defined needles, melting at $134^{\circ}$ : 
0.1794 gave $0.4300 \mathrm{CO}_{2}$ and $0.0924 \mathrm{H}_{2} \mathrm{O} . \quad \mathrm{C}=65 \cdot 36 ; \mathrm{H}=5 \cdot 72$.

$$
\mathrm{C}_{12} \mathrm{H}_{12} \mathrm{O}_{4} \text { requires } \mathrm{C}=65 \cdot 5 ; \mathrm{H}=5 \cdot 4 \text { per cent. }
$$

The substance gives no coloration with ferric chloride, and is insoluble in cold aqueous alkali. When warmed with this reagent, it slowly passes into solution. and acids precipitate another compound, which crystallises from dilute acetic acid in small needle clusters, melting at $141^{\circ}$, eliminating water vapour at a few degrees above this temperature, and then passing into the substance from which it was derived:

0.1578 gave $0.3506 \mathrm{CO}_{2}$ and $0.0834 \mathrm{H}_{2} \mathrm{O} . \quad \mathrm{C}=60.59 ; \mathrm{H}=5.87$. $\mathrm{C}_{12} \mathrm{H}_{14} \mathrm{O}_{5}$ requires $\mathrm{C}=60.5 ; \mathrm{H}=5.9$ per cert.

0.1271 required 5.35 c.c. $\mathrm{NaOH}$. solution (1 c.c. $=0.00785$ gram $\mathrm{NaOH})$.

$$
\mathrm{C}_{12} \mathrm{H}_{14} \mathrm{O}_{5} \text { (dibasic) requires } 5.44 \text { c.c. }
$$

It is evident that these two substances are related to one another as dibasic acid and anhydride, but we have not as yet succeeded in assigning any satisfactory constitution to them.

\section{Labile Ethyl Hydrogen $\beta$-Methylglutaconate, $\mathrm{CO}_{2} \mathrm{H} \cdot \mathrm{CH}_{2} \cdot \mathrm{CMe}: \mathrm{CH} \cdot \mathrm{CO}_{2} \mathrm{Et}$.}

This compound is formed in the experiment described above, but is difficult to obtain pure. It may be prepared by the action of alcoholic sodium ethoxide on the labile ester at the ordinary temperature, and can be isolated by shaking an ethereal solution of the product with aqueous sodium carbonate. It is a moderately viscous liquid, which does not appear to possess any tendency to crystallise:

0.2176 gave $0.4428 \mathrm{CO}_{2}$ and $0.1369 \mathrm{H}_{2} \mathrm{O} . \quad \mathrm{C}=55 \cdot 50 ; \mathrm{H}=6.99$.

$$
\mathrm{C}_{8} \mathrm{H}_{12} \mathrm{O}_{4} \text { requires } \mathrm{C}=55 \cdot 8 ; \mathrm{H}=7 \cdot 0 \text { per cent. }
$$

The acid ester passes into alcohol and the hydroxy-anhydride on distillation, and is converted into the labile acid on hydrolysis with aqueous potassium lydroxide.

Normal Ethyl $\beta$-Methylglutaconate, $\mathrm{CO}_{2} \mathrm{Et} \cdot \stackrel{\mathrm{CH}}{\mathrm{CH}} \cdot \mathrm{CHMe} \cdot \stackrel{\mathrm{C} H}{\mathrm{C}} \cdot \mathrm{CO}_{2} \mathrm{Et}$. - This ester is prepared by the esterification of the normal acid with alcohol and sulphuric acid, and is described in the literature. It yields the pure normal acid on hydrolysis with both acids and alkalis unless a large excess of the latter is used.

\section{Normal Ethyl Hydrogen B-Methylglutaconate, $\mathrm{CO}_{2} \mathrm{Et} \cdot \stackrel{\mathrm{C}}{\mathrm{C}} \mathrm{H} \cdot \mathrm{CHMe} \cdot \stackrel{\mathrm{C}}{\mathrm{CH}} \cdot \mathrm{CO}_{2} \mathrm{H}$.}

This substance occurs as a by-product in the etherification of the normal acid, and can be extracted by aqueous sodium carbonate. 
It crystallises from light petroleum (b. p. $70-80^{\circ}$ ) containing a little benzene, in long, slender needles, which melt at $73^{\circ}$ :

0.1960 gave $0.4005 \mathrm{CO}_{2}$ and $0.1256 \mathrm{H}_{2} \mathrm{O} . \quad \mathrm{C}=55 \cdot 72 ; \mathrm{H}=7 \cdot 12$.

$\mathrm{C}_{8} \mathrm{H}_{12} \mathrm{O}_{4}$ requires $\mathrm{Cl}=55 \cdot 8 ; \mathrm{H}=7 \cdot 0$ per cent.

The acid ester passes into alcohol and the hydroxy-anhydride when slowly distilled, and yields the normal acid on hydrolysis with alkali under the same conditions as those which transform the labile acid-ester into the labile acid. It is readily soluble in all the usual organic solvents excepting light petroleum.

\section{Labile Ethyl aß-Dimethylglutaconate, $\mathrm{CO}_{2} \mathrm{Et} \cdot \mathrm{CMe}: \mathrm{CMe} \cdot \mathrm{CH}_{2} \cdot \mathrm{CO}_{2} \mathrm{Et}$.}

In order to prepare this substance, 4.6 grams of sodium were dissolved in 55 grams. of alcohol and gradually mixed with 40 grams of ethyl isodehydracetate diluted with an equal volume of alcohol, the mixture being kept at $0^{c}$ throughout the process. Methyl iodide (31 grams) was then added, and the solution kept at about $5^{\circ}$ for two hours, when the reaction was brought to completion by gently warming on the water-bath. The ester, isolated in the usual manner, boiled at $142^{\circ} / 20 \mathrm{~mm}$. as a colourless, mobile oil :

0.1884 gave $0.4258 \mathrm{CO}_{2}$ and $0.1455 \mathrm{H}_{2} \mathrm{O} . \mathrm{C}=61.63 ; \mathrm{H}=8.58$. $\mathrm{C}_{11} \mathrm{H}_{18} \mathrm{O}_{4}$ requires $\mathrm{C}=61 \cdot 7 ; \mathrm{H}=8.4$ per cent.

The ester yields the normal acid (m. p. $148^{\circ}$ ) on hydrolysis with hydrochloric acid, and is converted into the labile acid (see below) on hydrolysis with alkali. The ethyl acetate formed in the reaction was recognised by its odour, but was not isolated.

\section{Normal Ethyl aß-Dimethylglutaconate, $\mathrm{CO}_{2} \mathrm{Et} \cdot \stackrel{\prime}{\mathrm{L}} \mathrm{Me} \cdot \mathrm{CHMe} \cdot \mathrm{U}^{\mathrm{H}} \mathrm{H} \cdot \mathrm{CO}_{2} \mathrm{Et}$.}

This substance is best prepared by the etherification of the normal acid with alcohol and sulphuric acid in the usual manner. It boils at $141 \% / 21 \mathrm{~mm}$. as a mobile liquid, closely resembling the labile ester in appearance:

$0 \cdot 2439$ gave $0.5495 \mathrm{CO}_{2}$ and $0 \cdot 1864 \mathrm{H}_{2} \mathrm{O} . \mathrm{C}=61 \cdot 45 ; \mathrm{H}=8 \cdot 49$. $\mathrm{C}_{11} \mathrm{H}_{18} \mathrm{O}_{4}$ requires $\mathrm{C}=61.7 ; \mathrm{H}=8.4$ per cent.

The ester gives the normal acid on both acid and alkaline hydrolysis.

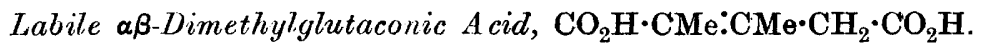

This acid, formed from the labile ester on hydrolysis with twice the theoretical amount of alcoholic potassium hydroxide, is obtained 
in a pure condition by recrystallisation from benzene, from which solvent it separates in small needles melting at $103^{\circ}$ :

0.1836 gave $0.3578 \mathrm{CO}_{2}$ and $0.1052 \mathrm{H}_{2} \mathrm{O} . \mathrm{C}=53.15 ; \mathrm{H}=6.37$. $\mathrm{C}_{7} \mathrm{H}_{10} \mathrm{O}_{4}$ requires $\mathrm{C}=53.2 ; \mathrm{H}=6.3$ per cent.

The acid is very unstable towards mineral acids, and in the above preparation care must be taken to liberate the acid from the potassium salt with the theoretical amount of hydrochloric acid; otherwise in the presence of excess of acid some of the labile modification is converted into the normal acid; in fact, the labile acid is much less stable in the presence of hydrochloric acid than the corresponding labile modification of $\beta$-methylglutaconic acid. The action of boiling aqueous potassium hydroxide which was found to convert the normal form of $\beta$-methylglutaconic acid completely into the labile modification (Feist) is only partly effective in the case of the higher homologue. The mixed acids produced in this manner can be readily separated, owing to the fact that the normal acid gives an insoluble, crystalline barium salt when the ammonium salt is treated with barium chloride and the solution is boiled:

0.3772 gave 0.2990 $\mathrm{BaSO}_{4} . \quad \mathrm{Ba}=46.61$.

$\mathrm{C}_{7} \mathrm{H}_{8} \mathrm{O}_{4} \mathrm{Ba}$ requires $\mathrm{Ba}=46.7$ per cent.,

whereas the salt of the labile acid remains in solution. The calcium salts of the two forms show the same difference in behaviour. The labile acid is more soluble in water than the normal acid.

The silver salt is a white, micro-crystalline powder:

0.3125 gave $0.1812 \mathrm{Ag}$. $\mathrm{Ag}=57.98$.

$$
\mathrm{C}_{7} \mathrm{H}_{8} \mathrm{O}_{4} \mathrm{Ag}_{2} \text { requires } \mathrm{Ag}=58 \cdot 06 \text {. }
$$

The labile acid is very stable towards boiling aqueous solutions of alkaline hydroxides.

\section{Labile Ethyl B-Methyl-a-ethylglutaconate, $\mathrm{CO}_{2} \mathrm{Et} \cdot \mathrm{CEt}: \mathrm{CMe} \cdot \mathrm{CH}_{2} \cdot \mathrm{CO}_{2} \mathrm{Et}$.}

This compound is prepared in the same manner as the dimethyl ester. It is a mobile liquid, which boils at $144^{\circ} / 15 \mathrm{~mm}$.:

0.2369 gave $0.5472 \mathrm{CO}_{2}$ and $0.1898 \mathrm{H}_{2} \mathrm{O} . \mathrm{C}=62.98 ; \mathrm{H}=8.90$.

$$
\mathrm{C}_{12} \mathrm{H}_{20} \mathrm{O}_{4} \text { requires } \mathrm{C}=63.2 ; \mathrm{H}=8.8 \text { per cent. }
$$

The ester yields the normal form of $\beta$-methyl- $\alpha$-ethylglutaconic acid (Trans., 1905, 87, 1709) when hydrolysed by acids, but is converted into the labile acid by alkalis. 


\section{Normal Ethyl $\beta$-Methyl-a-ethylglutaconate, $\mathrm{CO}_{2} \mathrm{Et} \cdot \stackrel{\mathrm{C}}{\mathrm{CEt}} \cdot \mathrm{CH} \mathrm{Me} . \stackrel{\mathrm{C}}{\mathrm{C}} \mathrm{H}_{2} \cdot \mathrm{CO}_{2} \mathrm{Et}$.}

The ester is formed from the normal acid on etherification by alcohol and sulphuric acid. It boils at $143^{\circ} / 15 \mathrm{~mm}$. :

0.2276 gave $0.5263 \mathrm{CO}_{2}$ and $0.1822 \mathrm{H}_{2} \mathrm{O} . \mathrm{C}=63.05 ; \mathrm{H}=8.89$.

$$
\mathrm{C}_{12} \mathrm{H}_{20} \mathrm{O}_{4} \text { requires } \mathrm{C}=63.2 ; \mathrm{H}=8.8 \text { per cent. }
$$

It is converted into the normal acid on both acid and alkaline hydrolysis.

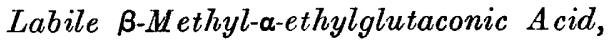 $\mathrm{CO}_{2} \mathrm{H} \cdot \mathrm{CEt}: \mathrm{CMe} \cdot \mathrm{CH}_{2} \cdot \mathrm{CO}_{2} \mathrm{H}$.}

This acid is formed by the hydrolysis of the labile ester with twice the theoretical amount of alcoholic potassium hydroxide, care being taken to add only the requisite quantity of hydrochloric acid to liberate the acid from its salt. It separates from either water or benzene in needle clusters, which melt at $98^{\circ}$ :

$\dot{0} \cdot 1753$ gave $0.3600 \mathrm{CO}_{2}$ and $0.1130 \mathrm{H}_{2} \mathrm{O} . \mathrm{C}=56.02 ; \mathrm{H}=7 \cdot 16$.

$$
\mathrm{C}_{8} \mathrm{H}_{12} \mathrm{O}_{4} \text { requires } \mathrm{C}=55.8 ; \mathrm{H}=7.0 \text { per cent. }
$$

The acid is more stable towards hydrochloric acid than the dimethyl acid, but is slowly converted into the normal modification when warmed with this reagent. It differs from the normal acid in being readily soluble in dry ether and in hot benzene; it is, moreover, more soluble in water than the higher melting acid. The barium and calcium salts of the two forms differ in the same way as the salts of the corresponding dimethyl acids.

The silver salt is a white, crystalline powder:

$$
\begin{aligned}
& 0.3210 \text { gave } 0.1791 \mathrm{Ag} . \quad \mathrm{Ag}=55 \cdot 79 . \\
& \mathrm{C}_{8} \mathrm{H}_{10} \mathrm{O}_{4} \mathrm{Ag}_{2} \text { requires } \mathrm{Ag}=55.95 \text { per cent. }
\end{aligned}
$$

The normal acid is converted into a mixture of the two modifications on prolonged boiling with strong aqueous alkali, the mixture being easily separated by means of the barium salts.

The Hydroxy-anhydride of $\beta$-Methyl-a-ethylglutaconic Acid (6-Hydroxy-4-methyl-3-ethyl-a-pyrone),

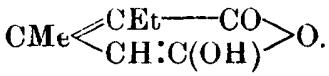

This substance is obtained with equal readiness both from the normal and iabile acids through the agency of acetyl chloride. It was described as the normal anhydride in a previous paper (Trans., $1905,87,1709$ ), and is best prepared by the method there given. It behaves on titration as a monobasic acid: 
0.3125 required 10.2 c.c. $\mathrm{NaOH}$-solution (1 c.c. $=0.0078$ gram $\mathrm{NaOH}$ ).

$$
\mathrm{C}_{8} \mathrm{H}_{10} \mathrm{O}_{3} \text { (monobasic) requires } 10.28 \text { c.c. }
$$

The hydroxy-anhydride is converted into the normal acid by hydration with water, and into the labile acid on treatment with dilute alkali in the presence of casein.

$$
\begin{gathered}
\text { The Hydroxy-anil of } \beta \text {-Methyl-a-ethylglutaconic Acid (3-Hydroxy- } \\
\text { 2-phenyl-5-methyl-6-ethyl-1:2-dihydropyridone), } \\
\mathrm{CMe}<<_{\mathrm{CH}}^{\mathrm{CH}-\mathrm{C}(0 \mathrm{H})}>\mathrm{NPh}
\end{gathered}
$$

This substance can be obtained either by heating the semianilide (Trans., $1905,87,1709$ ) at $150^{\circ}$, or by the direct action of aniline on the acid. In the latter case, 1.3 grams of acid were mixed with 0.7 gram of aniline, and heated at $150^{\circ}$ for fifteen minutes. The product was rubbed with a little pure ether, and recrystallised from this solvent. It formed long needles melting at $95^{\circ}$ :

0.2109 gave $0.5673 \mathrm{CO}_{2}$ and $0.1281 \mathrm{H}_{2} \mathrm{O} . \mathrm{C}=73.35 ; \mathrm{H}=6 \cdot 74$.

$$
\mathrm{C}_{14} \mathrm{H}_{15} \mathrm{O}_{2} \mathrm{~N} \text { requires } \mathrm{C}=73.4 ; \mathrm{H}=6.6 \text { per cent. }
$$

The anil is readily soluble in benzene, and dissolves in alkalis, behaving on titration as a monobasic acid:

0.2731 required 6.1 c.c. $\mathrm{NaOH}$-solution $(1$ c.c. $=0.0078$ gram $\mathrm{NaOH})$.

$$
\mathrm{C}_{14} \mathrm{H}_{15} \mathrm{O}_{2} \mathrm{~N} \text { (monobasic) requires } 6 \cdot 12 \text { c.c. }
$$

The colour of the indicator does not return on keeping, and the ring is not broken when the neutral solution is boiled.

The Sorby Research Labolatory,

The University, Sheffield. 